\title{
Does Russian English Exist?
}

\author{
Olga Bondarenko* \\ ESP Department, The Moscow State Institute for Tourism Industry n.a. Yu. Senkevich, Moscow, Russia \\ *Corresponding author: orbon@mail.ru
}

Received September 01, 2014; Revised September 11, 2014; Accepted September 17, 2014

\begin{abstract}
The researcher investigated and described the characteristic features of English of Russian EFL users in the context of World Englishes. Russian-like English in use is regarded at different levels, from pronunciation to syntactic structures and further to written and oral discourse. The Russian accent in English was studied through frequent and typical errors made by Russian natives and was interpreted as a cross-linguistic and cross-cultural phenomenon. Russian error analysis became the framework of this research. The analysis was made at several levels with contrastive analysis techniques involved and the results were explicated as negative interference. Both qualitative and quantitative analyses were undertaken, the results of which were summarized and illustrated with examples. The quantitative evidence was provided of error spread and individual error profiles, i.e. the most numerous types of errors in each individual error count and the most common combinations of such error type peaks. The research was based on the analysis of a considerable corpus of written and oral discourse samples featuring Russian errors in English made by Russians and collected by the researcher during the years of teaching practice from 2000 to 2014. The research results are suggestive of regarding Russian accent in English as a performance variety of English.
\end{abstract}

Keywords: World Englishes, English as a lingua franca, English as a foreign language, performance varieties of English, Russian English, the Russian accent, error analysis

Cite This Article: Olga Bondarenko, "Does Russian English Exist?" American Journal of Educational Research, vol. 2, no. 9 (2014): 832-839. doi: 10.12691/education-2-9-20.

\section{Introduction}

The global expansion of English results in the growing number of its varieties, as English is learned and spoken by people from various ethno-cultural backgrounds [1], [2].

The status of English in a non-Anglophone world may differ, from a second official language to a foreign language used in specific contests. As B. Kachru views it there is one universal trend of divergence of English varieties from the parent source. This is a result of certain characteristic changes in using English due to its contact with a particular foreign cultural and linguistic environment [3].

Expanding Circle countries, to which Russia belongs, are not immune to the process of divergence and deviation of English used there from the vernacular variant. The proof of it is in the acknowledged phenomena of Konglish, Chinglish and other Englishes.

English in Russia is a popular foreign language number one due to globalization of business and everyday communication. That is why the quantity of Russians using it in Russia is rapidly growing. They are businessmen, mass media people, politicians, EFL teachers, scholars, scientists, tourism and hospitality staff, professionals participating in international projects etc.. English as L2 is highly demanded.

You have to learn English in Russia mainly for three purposes, for studying abroad, work and leisure [4]. The process of learning and using English in communication is not going smoothly. According to one of the latest comparative "English First" Index' reports on English language proficiency among non-natives, Russia is rated $29^{\text {th }}$ among 54 countries of the world and proves to be the last in Europe after the Czech Republic, Poland and Slovakia. However, as Mr. Kent Johnson, the "English First" Chief Executive Officer in Russia admits, there is a positive trend. Russia's index has risen to 52.78 points as against 45.79 points two years ago [5].

It is believed by Russian linguists and educational experts that English will be still more popular in the course of time. Moreover, every cultured and educated Russian citizen will have a fluent command of English and will widely use it. It goes especially for ESP (English for special purposes) which paves the way for career success [6].

Unfortunately, the impression is that little is known about English used by Russians as there is neither a corpus of English used by Russian natives so far, nor extensive research work done in this direction ( at least evidenced by web resources.). Meanwhile the results of such a research may be demanded by teachers because of the growing number of Russian natives studying the English language and culture as well as by scholars studying World Englishes. The present research offers a glimpse of English used by Russians through investigating the most committed errors.

The 30-odd-year teaching experience of the researcher and the research results may prove that the English used 
by Russians mostly remains the same throughout decades with a set of similar errors described in detail further. Its flaws and instances of incongruity might be considered typical of Russian native speakers and thus characterize English used by Russians. What leads to such an inference?

- A list of communication-meaningful types of errors remained stable during a considerable period of time, as. the purposeful observations have been carried out for the last 14 years.

- A noticeable frequency and range of errors of the same type were observed in the samples of written and oral discourse produced by different Russian natives at different times and settings.

\section{Literature Review}

As mentioned above, Russia belongs to the Expanding Circle of the classical 3-circle model of International English described by B. Kachru [7]. It means that English has not any special status there. It is used as a means of communication between people of different language backgrounds in business, in travel, at international events, in private exchanges and interactions. "While speakers in the Outer Circle speech communities have both the need and the opportunity to use English in many daily situations, for most Expanding circle speakers using English as a lingua franca remains a rare adventure with changing partners, not part of their daily lives" [[8], p. 44]. However, the situation with the English language is developing and its role in Expanding Circle countries should not be underestimated. As Kirkpatrick observes, there is "tendency showing how Expanding Circle countries may be leading to the development of a local variety of English" [9].

English is used as a lingua franca(ELF) in Russia because "the Expanding circle has acquired ELF as its main function for English" [[8], p. 43]. English is also used by Russian natives, studying English, to communicate with each other for the sake of practice in classroom and out of classroom, orally and by email, performing certain communicative social functions and learning tasks in writing and orally.

This format of communication is not in line with Juliane House's definition of a lingua franca as a language for communication between members of two or more lingua cultures, for none of whom English is the mother tongue [10]. Nevertheless, it is indicative of Russian users' performance in English because it is situational, naturally initiated, is always addressed to the teacher, to a peer or a third person, and is carried out in various contexts.

There are two circumstances to emphasize. First, this Russian-Russian communication in English does not spare participants the trouble of keeping up with Standard English, that is using the language according to the norm. Second, it is true that this sort of communication is performed in sheltered settings by people with a common cultural background. Thus, they are relieved from the necessity to adjust to the interlocutor culturally. The latter fact suggests that the performance of Russian users of English under these conditions cannot be worse than in a natural intercultural setting but is likely to be similar to it or even better. These circumstances mean that the English used by Russians among Russians may become an object of research as a lingua franca with its own peculiarities. Researcher Alan Firth regarded ELF as a term referring to the use of English between speakers whose mother tongue is not English [11]. This definition perfectly meets the conditions of using English considered above and justifies Russian-Russian communication in English as a focus of investigating Russian English.

It is well known that "as learners, the speakers in the Expanding Circle are not given the right to their own variety-development, but are seen as norm-dependent" [[8], p. 42] D. Graddol emphasized that "English as a global lingua franca requires intelligibility and the setting and maintaining of standards" [12].

What does 'lingua franca' mean in practical terms? From the viewpoint of McArthur, it is "not the pidgin and creole 'Englishes' scattered throughout the world, or the 'fractured' or 'broken' English that other commentators have called (more conventionally) the lingua franca of world business. The answer in these instances has to be Standard English - an haute cuisine lingua franca if ever there was one" [[13], p. 1]. As S. Mollin argues, since ELF is not clearly described and remains "no stable variety as such" it makes ELF "a bad teaching standard”, thus, "the native norm should remain the teaching model in the Expanding Circle" [[8], p. 52]. In other words, the Engish as a Native Language (ENL) standard can be used as a benchmark to consider the degree of deviation from it by Russian users of English. Therefore the error is understood here as a deviation from the ENL norm. The norm, in its turn, according to B. Kachru, involves assumptions/hypothesis about:

- language production with reference to standards,

- language function with reference to models of English for communication genres, and

•assumptions about intelligibility [14].

Regarding the causes of errors, Graddol noted that "in the EFL world there is, by definition, no local model of English, though speakers' English accents and patterns of error may reflect characteristics of their first language" [[12], p. 11].

Moreover, "as English becomes more widely used as a global language, it will become expected that speakers will signal their nationality, and other aspects of their identity through English" [[15], p. 119]. McArthur is more direct saying that foreign accents in English are a reflection and construction of cultural identities [16].

Russian English (RE) has already attracted public attention. The term 'Runglish' was coined in 2000 for one of the languages aboard the International Space Station, a mixture of English and Russian [17]. However, such pigeon English used by Russians in limited contexts can hardly be characteristic of Russian users of English at large. Some researchers regard RE within the paradigm of the World Englishes in terms of translation issues. They acknowledge the practical significance of RE identity for the promulgation of Russian culture in the world [18], [19].

Alongside with the important mission of describing Russian culture and making it accessible for more people in the world, English serves communication in business and professional spheres. One of them is the sphere of education environment. The specific features of English used by Russian natives in this sphere may be representative of the local performance characteristics. 
There have been not so many comprehensive studies of Russian English so far, that is why this attempt is made to take a multi-sided look upon the characteristic features of English used by Russians.

\section{Objectives of the Research}

The research undertaken was aimed at three targets 1/ to characterize English used by Russian natives in terms of the most common deviations from the standard norms; $2 /$ to detect and categorize the regular errors in English made by Russian native speakers;

$3 /$ to specify the errors within the categories and to explicate what underlies them.

The hypothesis suggested is that the English of Russian users is characterized by a more or less stable array of qualities. These characteristics manifest themselves in typical errors that may be cross-linguistically and crossculturally rooted.

\section{Methods and Procedures}

The data analysis framework of the present research was the contrastive analysis of Lado [20] and the error analysis theory as part of the SL acquisition of Corder [21], and Selinker [22]. Methodologically contrastive analysis became the core of qualitative data processing, bringing out erroneous usage at several levels, starting with Russian-like pronunciation of sounds or spelling to, so to speak, "Russianalized" discourse (the term is mine - O.B.). An error analysis approach was applied to the collected field data, their description and interpretation.

The research carried out was a combination of longterm observations and a short-term recent cross-section study described below. The contingent of informants, chosen for this research, were Russian native learners of English using English in natural or quasi-natural contexts. The data were received from ESP students who came to get higher education at the Moscow Institute for tourism industry named after Yu. Senkevich, over the period of 2000-2014. During this period students' errors were regularly collected for identification, description, explanation and evaluation according to Corder's framework [21]. This set of participants was used for aggregating the most common errors and categorizing them. This stage of the research was of a qualitative character.

Besides, a quantitative cross section was undertaken in 2013-14. It embraced full-time day department students and correspondence students. The participants were male and female students and adult trainees aged 18-35 years working for a specialist diploma or a bachelor's degree. The total number of the participants in the 2013-14 study was about 150 informants in different academic groups. Their written and oral samples were investigated. Three kinds of discourse samples were analyzed: a/ oral contextual narratives b/ students' email messages to the researcher and $\mathrm{c} /$ written business genres important for ESP students of hospitality, such as business email messages, letters of complaint and apology, tour itineraries and leaflets etc.. Email samples represent an informal casual register and may be of interest as a transient form of discourse bridging the oral and written forms.

The students came from all over Russia, that is from the European part, the Urals, the Far East and Siberia, not only from the Moscow region, that is why the data received are considered to be representative of of the country as a whole.

As the focus of this research was on production only, there were two filters imposed on the material analyzed:

a/ errors in speech and writing were reviewed and no perception errors,

b/ errors harmful to communication were selected for review.

Both qualitative and quantitative methods were used to process the data as a whole. Qualitative methods included observation, making field notes, discourse analysis. Quantitative methods presupposed statistical processing of the data collected. The main stages encompassed

- empirical discovery of repeated errors, sorting them out and determining their typology;

- analyzing the errors and searching for their cause in cross-linguistic and cross-cultural terms;

- calculating the spread of error categories, that is counting the share of informants in the total number of informants who made errors of a certain type;

- calculating and ranging the top most 'resultative' error types per each informant.

\section{Findings and Discussion}

The author's and other researchers' contrastive analysis data were used to describe and interpret the differences between the two languages communication practices as potential causes of the English demonstrated by Russians. The data gathered by the researcher over the latest 14 years encompassed the regular repeated errors of Russian users of English. The Errors were categorized on the basis of linguistic levels according to their demonstration. Their analysis allowed to select the main types, which poise a certain constant difficulty for Russian users. They are syntactic errors, grammatical errors, lexical errors, pronunciation and spelling errors, discourse errors in written and oral modality.

\subsection{The Qualitative Analysis Results}

The repeated errors made by Russian users of English reveal some interesting trends. Below are the categories of regularly occurring errors with explications.

The modality of oral speech accounts for the most crucial and meaningful flaws in Russian English.

\section{Pronunciation Errors}

Pronunciation errors of the following kinds were discovered:

- Palatalization of consonants preceding sounds [i] and [e]: linen, seek

- Devocalization of consonants in the final position: peas=peace, tens=tense, said=sat, slaves [sleifs]

- Russian-like pronunciation of the interdental [ $\mathrm{\partial} \rightarrow \mathrm{d} /$ $\mathrm{z}]$ and $[\boldsymbol{\theta} \mathrm{t} / \mathrm{s}]$, and the interlabial $[\mathrm{w} \rightarrow \mathrm{v} / \mathrm{u}]$ :

e.g.This $\rightarrow$ [dis / zis], well $\rightarrow$ [vel / uel]

- Non-differentiated [3:] and [॰:] especially following [w]: work=walk. 
- Non-differentiation of vowel length, e.g. [u] and [u:], [i] and [i:]: pool=pull, live=leave, port=pot etc.

- Wrong stress in conversives (export, adult, subject) and in multi-syllable words (deve'lopment, oc`cupancy, penin`sula);

- Russian-like pronunciation of lexis especially that with international roots

e.g. Christianity [khristi`æniti], architecture [`a:khitektfə], civilization [tsivilai zei $[\mathrm{n}$ ].

Some scholars interpret the pronunciation differences between native and non-native speakers of English by the existence of phonological stereotypes distinguishing in different ethnic communities [23].This may account for the palatalization and devocalization effects in Russian English pronunciation. Devocalization of final consonants as well as palatalization are typical of the Russian traditional pronunciation and thus may impact the pronunciation of English discourse. Apart from that, it has been noted by Cheryl Posey that "Russian sounds are generally pronounced more harshly than American English sounds" [24]. In particular, Russian [kh] is more fricative than English [h ].

On the other hand the length of vowels is not a phonemic feature differentiating meaning in Russian, that is why the informants' knowledge of the fact that it is not so in English does not become one of the focuses in their performance.

Besides Russians naturally have difficulty with the English sounds that are not available in the Russian language, for example [w], [ð], [ө]. In accordance with the physiological law of effort-saving they tend to replace these sounds with similar native ones $[\mathrm{v}]$ or $[\mathrm{u}],[\mathrm{z} / \mathrm{d}]$, $[\mathrm{s} / \mathrm{t}]$. It may change the meaning and impair communication considerably.

\section{Lexical Errors}

Lexical failures are manifested in the wrong choice of the English equivalent out of two or more synonyms or homonyms, when there is no strict one-to-one correspondence between English and Russian. This multivector Russian-English lexical correlation leads to numerous errors, such as the ones below:

сказать - tell or say? (I'll tell about it later. Say the head waiter about it)

ожидать - wait or expect? (We are waiting for your reply)

последний - the last or the latest? (How was your last session?)

получать - receive or accept? (Do you receive cash?)

проживать в отеле - stay or live at a hotel?

салон - cabin, lounge, parlour or salon?

чек - invoice, receipt or cheque?

кухня - kitchen or cuisine?

номер - number or room (in a hotel)?

These errors are due to the fact that there are crosslinguistic differences of both paradigmatic and syntagmatic character, stemming from the asymmetry of the semantic fields and the word value in the two languages systems on the one hand, and from different distribution of correlating words on the other hand, which poises a difficulty for Russians.

Attempts to provide direct literal translation from Russian into English are also doomed to failure:

How do you call it in English? (This is a literary translation from Russian "Как вы называете это поанглийски?)
I wish you from my heart happiness ( Я желаю вам от всего сердца счастья)

You could go to the bar and miss a glass of wine there instead of "have a glass of wine" because in the Russian set expression "пропустить стаканчик" the first word means "to miss (a train)", the second means "glass" but the whole word combination is an idiom with a meaning of its own ("have a drink").

Similarly a set expression "in the near future" is often translated into "in the nearest future" only because in the Russian corresponding collocation the word "near" (близкий) is always used in the superlative degree (ближайший: в ближайшем будущем).

A lot of lexical mistakes are caused by the difference in collocation between the Russian and the correlating English word

e.g. We cannot decide this question (problem).

Russian "вопрос" may mean a "question" and an "issue" in English, which are not decided, but asked, posed or settled. In Russian we can "решить" a question, an issue, a problem, a situation and what not, which provides a negative transfer effect in communication in English.

Phrasal verbs and the right-hand valence of the English verb are another cause of Russian failures. This phenomenon is foreign to the Russian language system and Russian mind as the meaning of a Russian verb does not depend on the postpositions following it

e.g. Who looks for your disabled father?

False cognates are another source of errors. There are quite a number of lexical units similar in form but different in meaning in both the languages, which leads to contextual incongruity and misunderstanding. For instance, Russian "факультет" seems identical with 'faculty', but means 'department of a college or university' only. The semantic spectrum of 'faculty' is wider thanks to 'an aptitude for doing something' and 'the teaching or research staff of a university or college, viewed as a body' [25]. Similarly the Russian "профессор" is the top academic rank and position at a department of a higher educational institution, while the Anglo-Saxon system of professorship is more elaborate and requires specification of what kind of professor is meant, full, associate or assistant. In other words, the differences in false cognate pairs are a source of errors, which have a cross-cultural origin, implying different traditions, ways of life and systems of realia.

Paronyms are also an area of considerable trouble. Confusion of English words similar in form but different in meaning has turned out to be one of the distinguishing features of Russian English, for instance the following pairs of words are the permanent stumbling block for Russian natives: personnel and personal, economic and economical, quite and quiet, rise and raise, lie and lay, suit and suite, salon and saloon (e.g. There is a beauty saloon at your disposal in our hotel) etc.

Unlike phrasal verbs paronyms are not foreign to the Russian language system, but probably become the cause of trouble because they have to be assumed and employed by Russian users within a foreign sign environment.

Coinage mania. Russian users of English have often been caught at coining a lexical blend distorting the correct English word to tailor its material form to the Russian equivalent, e.g. 
'organizator' (организатор) instead of 'organizer'

'touristic' (туристический) instead of 'tourist' or 'tourism'

'vanilin' (ванилин) instead of 'vanilla'

'degustation' (дегустация) instead of 'wine-tasting'

'automatization' (автоматизация) instead of

'automation'

'annullation' (аннуляция) instead of 'cancellation' etc.

As it can be seen from the examples, the problem concerns international lexis, which seems to belong to both the languages.The international roots of these words play a bad joke with Russian users, because they think that it is quite enough to slightly change the form of the Russian versions of these words towards English in order to use them in English discourse.

Summarizing the lexical error analysis we find echoing ideas in the previous studies of other researchers. It is hard not to agree with Wasserscheidt, that "language nonselectiveness in speech production means that all units in the lexicon whose semantic properties are in accordance with the concept the speaker wishes to express are activated" (italics is mine - O.B.) [26].

\section{Grammatical errors}

The analysis of grammar norm deviations has shown several evident groups of norm violation types. The most massive is the group of omitted articles (especially the indefinite "a") and misused articles. As these mistakes can rarely destroy communication, they are not reviewed in this paper.

As it was mentioned above, the right-hand valence of English verbs and participles and the prepositions that follow them are the area of special concern for Russian users and the source of numerous errors. They include omitted and wrong prepositions, for example

a/ Children travel with a discount (instead of "at a discount").

b/ There are 53 apartments deluxe category at our resident hotel (instead of "of a deluxe category).

c/ You can get there by foot (instead of "on foot") or on your car (instead of "in your car").

d/ I will call to the hospital (instead of "call the hospital").

e/ How can we contact with you? (instead of "contact you").

f/ I would like to fly by first class (instead of "fly first class").

$\mathrm{g} /$ It is a room with a nice view on the park (instead of "of the park").

h/ I entered into the university in 2012 (instead of "entered the university").

The above very typical Russian mistakes demonstrate the effect of negative transfer when the presence of the Russian preposition in the correlating contexts is unnecessary in English (d, e) or misleading (c, g, h). The idea underpinning numerous preposition mistakes of Russian users of English is the cross-linguistic difference in word linking and cohesion within a sentence, as in Russian it is achieved not so much by means of prepositions, but by flexions.

English used in production by Russians has shown verb tense and voice errors. The most frequently occurring ones are the following:

- The Simple Tenses used instead of the Continuous and Perfect tenses e.g. Why are you looking so happy? - I'll go on holiday. I work at this company for 5 years now.

This monument did not survive to nowadays.

- The Future tenses in clauses of time and condition instead of the present tenses

e.g. If you will agree to our terms, we will offer you a discount.

If you will not refund us the money, we will take our business elsewhere).

- Avoidance or misusage of the gerund

e.g. We are looking forward to consider the options.

Do you mind wait a minute?

- Grammatical disagreement

e.g. There are a cafe and two restaurants at the hotel. The staff was friendly. This tours. A technical problems.....Those who wants.....

- Part-of-speech errors

e.g. Are you agree? I have already lunched. The expire date is ...I apology for the inconvenience.

- Ignoring the $-\mathrm{s}$ in the third person singular verbs.

- Voice errors

e.g. The meeting will hold at the conference room.

The linen changes every three days.

- Misusage of grammar categories

e.g. I'm feeling myself fine.

Practically all the above types of errors may be 'provoked' by Russian grammar categories and structures with their interfering impact on the newly formed cognitive frames in English. Thus, phenomena that are not universal or common to both the languages seem to cause errors. The gerund, "there is/are" structure, the third person singular, the Continuous and Perfect aspects of the tense system have no markers in Russian, that is why they are especially hard to be produced in English by Russian natives. On the other hand, the future tense is very often used in Russian clauses of condition and time, thus provoking Russian users to future tenses in English clauses of time and condition too. The Russian equivalent propositions about the meeting and the linen use the Active voice reflexive verbs (состоится, меняется), which creates a misleading illusion of the subject coinciding with the agent of action in English. The combination "to have lunch" is rendered by one verb in Russian (обедать), which encourages a Russian to convert the noun "lunch" into the non-existing verb. The use of reflexive pronouns and superlative forms of adjectives where they are not needed can be explicated by the possible option for Russian English users to follow literally Russian collocation patterns (Чувствую себя хорошо). Thus, differing native grammar substratum tells on the English used by Russians making it Russian-like.

The above results of the Russian grammatical error analysis confirm other researchers' conclusion that in second language acquisition "transfer may occur on all levels of language production" [7,27], and " in all linguistic subsystems, including morphology and syntax" $[12,28]$.

\section{Syntactic errors.}

Syntactic errors are erroneous combinations of language elements at the level of a sentence resulting in distorted meaning and misunderstanding. Since the sentence is a complete semantic structure and an important unit of communication, errors at its level may be especially detrimental to the sense and can ruin communication. 
The research discovered the following types of repeated syntactic errors.

1. Omission of a copula-verb predicate scored a record number of occurrences.

e.g. The cost of the tour per person $\$ 500$.

The bar and the restaurant at your service.

2. Wrong word order in statements and especially in direct and indirect questions, ignoring the fixed English word order.

e.g. Will be prepared a social programme for the participants. From the hotel it is easier to get to the centre than from the airport.

The fruit of my effort you can find here.

I'd like to ask you may I make a presentation.

How much the tuition will cost?

3.Wrong word order in word combinations.

e.g. The service was not enough fast.

I stayed at the room deluxe.

Our meal plan B/B included continental breakfast.

Also Egyptians built amazing pyramids.

4. Wrong verb government and verbal pattern and as a result a wrong syntactic structure.

e.g.We apologize that we kept you waiting.

I wish you to have a good day.

Thank you a lot that you have corrected the paper.

I'd like to draw your attention that one person per group of 20 is free.

I suggest to join the Silver Card programme.

We offer you to arrange conferences here all year round.

5. Double subject.

e.g. Julia and I, we are back home. The general, he was not old.

6. Omission/deletion of the subject.

e.g. Wish you a wonderful year!

7. There is a vernacular syntactic structures problem. Such structures as the Complex Object $\mathrm{V}+\mathrm{N}+\mathrm{V}$, Complex Subject $\mathrm{N}+\mathrm{V}+\mathrm{V}$ (infinitive), 'to have something done' and some others are misused or not used at all when they are required.

e.g. I want that the next year will be filled with joy.

'Say that the prices will go up soon' instead of 'The prices are said to go up soon.' 'Can I translate this text into Japanese?' instead of 'Can I have this text translated into Japanese?'

The most frequent and numerous error of omitting the copula verb is due to the fact that it is always omitted in the present tense in Russian. Omission of the subject by Russian users of English can be explained by the developed category of conjugation of the Russian verb, that is its change according to the singular and plural number and 3 persons, which is fixed in the verb flexion. It makes it superfluous to use the subject and it is often omitted in speech. This practice is transferred on to English by Russian users (\# 6).

It is common knowledge that the English language has a fixed word order both in affirmative and interrogative sentences [[29]: pp. 62, 64, 66, 68, 74]. On the contrary Russian word order is loose and does not radically change the meaning of the utterance. This presupposition is very likely to impact the English interlanguage (the term of Selinker [22]) of Russian users of English subconsciously (\# 2, 4).

It was emphasized by other researchers, Lynn Visson for example, that English natives place the most important information at the beginning of a sentence embodying it in the subject, while in Russian the most crucial part is left for the end. This peculiarity makes ENL speakers wait in suspense and irritation as if their Russian English speaking interloculor was playing at hide-and-seek instead of getting down to the gist [29].

Of special interest is a very common error in the word order of $\mathrm{N}+\mathrm{N}$ attributive word combinations in English, where the role of an attribute is always played by the first noun. However, in Russian the exact reverse is the case and the attributive use of the second noun is transferred to communication in English (\# 3). The use of "enough" becomes tricky for Russians only in combination with adjectives where inversion applies, contradictory to the corresponding Russian word combinations Adv+Adj (достаточно быстрое обслуживание). The coinciding structure ENOUGH $+\mathrm{N}$ in both Russian and English causes no errors. A very typical mistake of opening a sentence with 'Also' is a syntactic calc from Russian (Также....) (\# 3).

This research provided evidence that alongside with misusage and omission of certain syntactic elements, there is a persistent resistance to specific, if not unique, syntactic structures. Russian users of L2 avoid structures that they find 'foreign' and difficult, they do not 'feel' their appropriateness. Thus, the effects of L1 come out not only in errors, but in avoidance of proper structures (\# 7). In spite of any teaching and learning effort such structures are normally avoided or distorted by Russian users. This tendency of avoidance is notably confirmed by another Russian researcher Anna Charitonova [27], who proved that Russians avoid using English phrasal verbs more often than Norwegians, whose language belongs to the same group of Germanic languages as English.

\subsection{The Quantitative Analysis Results}

The quantitative findings of the cross-section research are summarized in two tables. The first shows the spread of the errors of regular types, that is the average percentage of the informants of several groups of students who made errors of a certain type.

Table 1. Spread of Errors

\begin{tabular}{|c|c|c|c|}
\hline Type ofErrors & $\begin{array}{c}\text { Oral Discourse } \\
\text { Samples }\end{array}$ & $\begin{array}{c}\text { Written Email } \\
\text { Samples }\end{array}$ & $\begin{array}{c}\text { Written Other } \\
\text { Samples }\end{array}$ \\
\hline Discourse & $20 \%$ & $32 \%$ & $48 \%$ \\
\hline Syntactic & $40 \%$ & $53 \%$ & $66 \%$ \\
\hline Lexical & $25 \%$ & $46 \%$ & $34 \%$ \\
\hline Grammatical & $40 \%$ & $53 \%$ & $60 \%$ \\
\hline Article & $25 \%$ & $47 \%$ & $67 \%$ \\
\hline Spelling & & $46 \%$ & $44 \%$ \\
\hline Punctuation & & $40 \%$ & $21 \%$ \\
\hline Pronunciation & $75 \%$ & & \\
\hline Intonation & $30 \%$ & & \\
\hline
\end{tabular}

The data in Table 1 show the average number of informants in different groups who made particular types of errors in discourse of three modalities, i.e. oral, email and written. As it can be seen, the most widely spread errors are made by Russian natives in article usage, grammar and syntax in writing, and in pronunciation, grammar and syntax in oral speech. The more formalized and regulated the discourse was, the wider was the spread of the error type, that is more persons made similar mistakes in emails than in oral discourse, and still more 
persons made them in written genres as compared to email messages. Anyway, the modality of communication did not affect the dominant error zones, they were the same as mentioned above. The numbers of informants making syntactic and grammatical errors are practically correlating in all the three modes of samples. It can be interpreted as a proof of the fact that there are modalityfree types of errors. They objectively reflect the phenomena in L2 that are hard to assume for Russian natives.

Table 2. Individual Error Profile

\begin{tabular}{|c|c|c|c|}
\hline Name of informant & Number a & ype of Errc & \\
\hline Dok & 12 Pron & 4 Dis & \\
\hline Rog & 10 Pron & $5 \mathrm{Int}$ & \\
\hline Ale & 10 Pron & & \\
\hline Trof & 7 Pron & & \\
\hline Kap & 6 Pron & & \\
\hline Abr & 6 Pron & & \\
\hline Zait & 5 Pron & 4 Gram & $4 \mathrm{Int}$ \\
\hline Shar & 4 Gram & & $4 \mathrm{Int}$ \\
\hline Xen & 10 Gram & & $4 \mathrm{Int}$ \\
\hline Zhur & 10 Dis & 5 Gram & \\
\hline Kom & 4 Syn & 9 Gram & \\
\hline Tka & 5 Dis & 8 Gram & 7 Lex \\
\hline Krol & 6 Dis & 5 Gram & \\
\hline Kolp & & 4 Gram & \\
\hline Flor & 4 Dis & 17 Syn & 26 Gram \\
\hline Fuf & 14 Dis & 4 Lex & \\
\hline Chep & 8 Dis & & \\
\hline Krup & 8 Dis & & \\
\hline Pal & 6 Dis & & \\
\hline Bagr & 6 Dis & 7 Gram & \\
\hline Vor & 4 Dis & & \\
\hline Ign & 13 Dis & 4 Syn & \\
\hline Yur & 8 Dis & & \\
\hline Hor & 7 Syn & 5 Lex & \\
\hline Lim & 4 Dis & 5 Syn & 12 Gram \\
\hline Okay & 5 Dis & 6 Syn & 13 Gram \\
\hline Grig & 8 Lex & 14 Gram & \\
\hline Nad & 5 Dis & 4 Syn & 11 Gram \\
\hline Ego & 4 Dis & 4 Syn & 7 Gram \\
\hline Mor & 4 Lex & 4 Syn & 6 Gram \\
\hline
\end{tabular}

The second table demonstrates individual error profile indicating the flat number of mistakes of each type committed by each informant throughout his or her discourse samples both orally and in writing. There were 30 persons randomly selected out of 150 informants. The surnames were shortened beyond recognition for the sake of confidentiality and look like pseudonyms. Only numerous errors were included in Table 2, that is those numbering 4 and more occurrences of errors of a certain type per individual. Less numerous errors were considered occasional and were discarded.

A brief review of Table 2 allows to make certain inferences:

a/ The peak number of individual errors falls on grammar (26), syntax (17), discourse (14) and pronunciation (12).

b/ The ranging of errors in the individual score features grammar errors ranking first among the error types described in the qualitative analysis part of the article. The majority of error peaks made by 12 out of 30 persons were grammar errors. Discourse errors rank second (8 out of 30 persons' most numerous errors pertained to discourse). They encompassed violations of the L2 rules of layout, register and speech strategies stereotypically applied by natives in the genres in question. Discourse errors are not on the surface, are harder to interpret and can be construed by cross-cultural and cross-communicative interference. The third rank is shared by syntactic (5 persons out of 30) and lexical errors (4 persons out of 30 ).

c/ Single (16 persons), double (9 persons) and treble (5 persons) error peaks were observed.

d/ Some categories of errors never numbered peak scores in individual sample corpora: They are lexical and intonation errors.

e/ Error combinations provide evidence about the dominating grammar plus discourse and grammar plus syntax pattern of error peaks in individual sets.

f/ The above mentioned types of errors correlate with the data in Table 1 and seem to be the areas of high risks for Russians and the most likely zones of contamination in English used by Russians. They are English grammar and syntax, discourse and pronunciation.

The implication of the described above procedures is the proposition that particular erroneous usages of the majority of participants, occurring repeatedly and coinciding with the top individual frequent errors, may be indicative characteristics of a modern Russian accent in English.

\section{Conclusion}

Summarizing this research, it can be stated that, although Russian English is not an ethnic or geographical variety of English, it exists. Unlike ESL, which is a product of local nativisation and acculturation, EFL used by Russians is not a result of their creative potential in terms of language structure and function, but is likely to derive from cross-linguistic, cross-cultural and crosscommunicative interference.

'Russianalization' is a multy-level phenomenon accounting for the Russian accent in English. Similar errors regularly repeated and widely spread among Russian users of English are characteristic of various age groups, status and region of Russia as well as of different command of English. It may be suggestive of consistent patterns of English usage peculiar to Russian natives. This multiple accent requires further research and may be manifestation of the Russian performance variety of English.

The results of this research may be interesting from pedagogical perspectives and can be helpful in teaching EFL to Russians by English natives and other foreign instructors, as normally they are unaware of the above mentioned pitfalls. It can also trigger off further research aimed at describing the ethnic affiliation of non-native English users in terms of the specificity of error types and error combinations.

\section{References}

[1] Crystal, D. English as a Global Language. Cambridge University Press. Cambridge, UK, 2003, 228 [Accessed July 20, 2013]. 
[2] McKay, Sandra Lee. Teaching English as an International Language: Rethinking Goals and Approaches. Oxford University Press, Oxford, UK, 2002, 160.

[3] Kachru, B. Asian Englishes: Beyond the Canon. Hong Kong University Press, Hong Kong, 2005. 333p.

[4] E-resource: "Английский язык. Причины актуальности и перспективы изучения" [Angliysky yazyk. Prichiny aktualnosty i perspectivy izuchenia] Available: www.english-lessons-moscow.ru/english_language.html.

[5] E-resource Molnet.ru. Available: http://www.molnet.ru/mos/ru/science/o_61456?VOTING_ID=21 \&QUESTION_ID=24 [Accessed December 14 2013].

[6] E-resource: "RIA Novosti" Available: news.mail.ru/society/8737228/ [Accessed December 14, 2013].

[7] Kachru, B. "Standards, Codification and Sociolinguistic Realism: The English Language in the outer circle". In: Quirk R. Widdowson H. (Eds.), English in the World. Cambridge University Press, Cambridge, UK, 1985.

[8] Mollin, S. "English as a Lingua Franca: A New Variety in the New Expanding Circle". Nordic Journal of English Studies, 5 \# 2. 41-57. 2006.

[9] Kirkpatrick, A. World Englishes. Implications for international communication and English language teaching. Cambridge University Press, Cambridge, UK, 2007, 265.

[10] House, J. "Misunderstanding in intercultural communication: Interactions in English as a lingua franca and the myth of mutual intelligibility". In: Gnutzmann, C. (Ed.) Teaching and Learning English as a Global Language. Stauffenberg, Tübingen:, Germany. 1999, 73-93.

[11] Firth, A. The discursive accomplishment of normality: On 'lingua franca'. English and conversation analysis. Journal of Pragmatics. 26, 237-259, 1996.

[12] Graddol, D. The Future of English? The British Council. London, UK, 1997. Available: http://www.britishcouncil.org/learning-eltfuture.pdf [Accessed January 10, 2014].

[13] McArthur, T. World English and world Englishes: Trends, tensions, varieties, and standards. Language Teaching, 34, pp 1-20, 2001.

[14] Kachru, B. English as an Asian Language. Links \& Letters, 5, 89108, 1998.

[15] Graddol, D. English Next. The British Council. London, UK. 2006. Available: http://www.britishcouncil.org/learning-research-english-next.pdf [Accessed May 30, 2014].

[16] McArthur, T. "CODE-MIXING AND CODE-SWITCHING." Concise Oxford Companion to the English Language. 1998. Encyclopedia.com. 31 Aug. 2014 Available: www.encyclopedia.com [Accessed April 17, 2013].

[17] Feuer, A. For the Thirsty Runglish Speaker: Try an Ized Ciawfeh. The N.Y. Times 14 June 2005. Available:
http://query.nytimes.com/gst/fullpage.html?res=9E01E3DD133EF 937A25755C0A9639C8B63 [Accessed June 15, 2014].

[18] Кабакчи, В. Англоязычное описание советской культуры. Ленинград: Ленинградский государственный педагогический университет им. А.И. Герцена [Kabakchi, V. (1985) Angloyazychnoye opisanie sovetskoy kultury. Leningrad, the USSR: The Leningrad State Pedagogical University n. a. A.I. Herzen]. 1985.

[19] Proshina, Z. "English as a Lingua Franca in Russia". Intercultural Communication Studies, XVII. 4. 125-140. 2008.

[20] Lado, R. Linguistics across cultures:Applied Linguistics for Language Teachers. University of Michigan Press, Michigan, 1957, 141.

[21] Corder, S.P. “The significance of learners' errors”. International Review of Applied Linguistics, 5. 160-170. 1967.

[22] Selinker, L. “Interlanguage”. IRAL, 10 (3). 209-231. 1972.

[23] Лаврова О. А. О фонологической компетенции: особенности английской спонтанной речи. Дисс. .... канд пед наук. Москва: МГЛУ [Lavrova, О.A. O Fonologicheskoy Competentsii: Osobennosty Angliyskoy Spontannoy Rechy. Thesis. Moscow State Linguistic University, Moscow, Russia, 2010, 230].

[24] Posey, Ch. "Speaking Your Best. Russian Accent Reduction", Speaking Your Best Inc. [Online] Available:

http://www.speakingyourbest.com/accentguides/russianaccent.htm 1 [Accessed June 29, 2014].

[25] Oxford Dictionaries, Oxford University Press, 2014 [Online] Available: www.oxforddictionaries.com/ [Accessed March 30, 2014].

[26] Wasserscheidt, Ph. "Constructions do not cross languages. On the internal structure of constructions and bilingual language use ”. In: Hilpert M., Östman J.-O. (Eds.). Constructions and Frames, Humboldt-Universitat zu Berlin \& Freie Universitat Berlin, Berlin (forthcoming). Available: http://www.academia.edu/3708561/Constructions_Do_Not_Cross LLanguages_On_the_internal_structure_of_constructions_and_bili ngual_language_useWasserscheidt [Accessed May 30].

[27] Odlin, T. Language transfer. Cross-linguistic influence in language learning. Cambridge University Press, Cambtidge, 1989.

[28] Kharitonova, A. Lexical transfer and avoidance in acquisition of English phrasal verbs. MA Thesis. University of Oslo, Oslo. May 2013. Available:

https://www.google.ru/url?sa=t\&rct=j\&q=\&esrc=s\&source=web\& cd=2\&ved=0CCYQFjAB\&url=https\%3A\%2F\%2Fwww.duo.uio.n o\%2Fbitstream\%2Fhandle\%2F10852\%2F37028\%2FKharitonovaMaster.pdf\%3Fsequence\%3D1\&ei=QysPVOfBD6K_ygPFIICICQ \&usg=AFQjCNFmtYj_G5bXPbRJcAb1UzWrbrwXSA\&bvm=bv. 74649129,d.bGQ\&cad=rjt [Accessed June 11, 2014].

[29] Coe, N., Harrison, M., Paterson, K. Oxford Practice Grammar. Oxford University Press, Oxford, UK, 2006, 296.

[30] Visson, L. Where Russians Go Wrong in Spoken English: Words and Expressions in the Context of Two Cultures. R.Valent, Moscow, Russia, 2005, 191. 